\title{
Experimental Investigations on Tilting Pad Journal Bearings
}

\author{
RENATO BRANCATI ${ }^{\mathrm{a}, *}$, STEFANO PAGANO ${ }^{\mathrm{a}}$, ERNESTO ROCCA ${ }^{\mathrm{a}}$, MICHELE RUSSO ${ }^{a}$ \\ and RICCARDO RUSSO ${ }^{\mathrm{b}}$ \\ a Dipartimento di Ingegneria Meccanica per l'Energetica, Università di Napoli "Federico II", Napoli 80125, Italy; \\ ${ }^{\mathrm{b}}$ Dipartimento di Ingegneria Meccanica, Università di Salerno, Italy
}

(Received 23 April 1998; In final form 17 June 1998)

\begin{abstract}
The results of a survey conducted on an experimental system consisting of a rigid rotor supported on two radial bearings each with five tilting pads is presented. In particular, the system was set up in order to assess the dynamic behaviour of the bearing in unusual operating conditions. The response of the bearing to different unbalance values was determined after acquiring and analysing the orbits described by the journal axis for assigned unbalance values in different operating conditions. Analysis of the results shows some particular operating features that were not entirely predicted by the theoretical model and which may give rise to malfunctions in the rotor-tilting pad bearings system. The tests were carried out in the rotor dynamics laboratory of the Dipartimento di Ingegneria Meccanica per l'Energetica at the University of Naples.
\end{abstract}

Keywords: Tilting pad journal bearings, Lubrication, Rotor-bearing system, Journal orbits, Stability

\section{INTRODUCTION}

The correct and safe dynamic behaviour of a rotor is characterised by an axis motion synchronous with rotation and with a small amplitude. Ideally the axis of a perfectly balanced rotor should have no motion at all and is located in the stationary equilibrium position, but the effective axis motion is due to residual unbalance that is present even after a properly performed balancing operation.
However, in technical practice rotors often display a significantly different behaviour from optimal operation and this can lead to problems that may even reach serious levels.

Malfunctions of this kind, characterised by journal axis motions that have a large amplitude and frequencies that may well be different from that of the rotation speed, can be caused by various factors and are often difficult to identify because of the complexity of modern rotor machines.

* Corresponding author. Fax: (39)(81) 2394165/(39)(81) 7681111. 
One of the known causes of malfunctions can be attributed to excessive unbalance and the intrinsic behaviour of certain machine components, such as bearings, seals, the machine base, and so on.

The aim of the present paper is therefore to conduct an experimental analysis of the dynamic behaviour of tilting pad journal bearings and to examine the possibility that they may themselves be the cause of abnormal machine operation.

This type of bearing is extensively employed in turbo-machinery because of its stability to oil whirl: an essential property given the high rotation speeds of modern turbo-machines and one which justifies the use of tilting pad bearings instead of traditional cylindrical bearings. Although the tilting pad bearing has been in use for some time, some features of its behaviour in unusual operating conditions have not yet been analysed and a basic investigation therefore seems to be worth conducting.

Bearing behaviour can only be analysed if the bearing itself is unaffected by other machine components; consequently, this study considers a rotorbearing system with rigid rotor and bearing supports and which is symmetrical along the centre plane orthogonal to the rotation axis. In a system of this type, the only acting force is due to the unbalance and the resulting axis motion is determined by the behaviour of the bearings alone.

Since the system is symmetrical the computer simulation can be carried out considering only one of the two bearings and half the rotor mass. Thus the number of motion equations is equal to the number of tilting pads plus two more for the motion of the journal centre. The motion equations are relatively easy to write as the Reynolds theory makes it possible to calculate the hydrodynamic forces between the pads and the journal and, for a given bearing, the Sommerfeld number and the dimensionless unbalance are the only parameters on which system operation depends, at least in normal operating conditions. Whereas anomalous bearing behaviour has to be investigated through experimentation on a physical model which, although conceptually simple, is plagued by a series of difficulties deriving from the fact that the operating parameters included in the Sommerfeld number, on which bearing behaviour depends, are numerous, highly variable and interdependent.

In view of the above, the experimental system was set up with as few elements as possible so as not to introduce sources of error. Hence it is made up of a rigid rotor, whose unbalance can be varied, mounted on two journal bearings with five tilting pads.

The present paper first gives a brief description of the numerical simulation code, which provides the rotor's 'nominal' behaviour and is a useful guide for interpreting the experimental results, and then illustrates the experimental system and the results obtained.

Analysis of the results shows some particular features of bearing behaviour which theoretical simulation does not predict.

\section{THEORETICAL BACKGROUND}

The system analysed in the investigation consists of a rigid rotor supported on two journal bearings with five tilting pads in the 'load on the pad' configuration (Fig. 1).

The rotor-bearings system is symmetrical with respect to the rotor's centre plane, which makes it possible to study just one of the two parts into

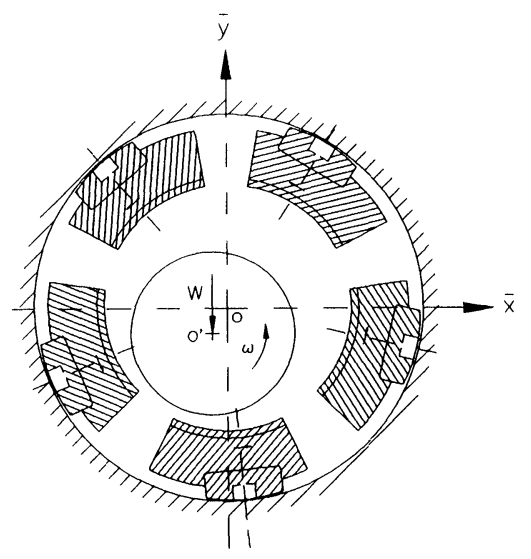

FIGURE 1 Bearing sketch 
which the system is divided by this plane and which consists of one bearing and a journal whose mass is equal to one half that of the rotor.

The dynamic simulation of the journal-bearing system is achieved by integrating the motion equations which, in the case in question, form a set of 7 differential equations, the first two of which represent the translatory motion of the journal, and the others the oscillatory motion of each pad around its pivot. Adopting a fixed reference system $O_{\bar{x} \bar{y} \bar{z}}$ whose $\bar{z}$-axis has the rotor speed direction $\omega$ while the $\bar{y}$-axis has the load direction, and using the dimensionless quantities listed in the nomenclature, the dimensionless motion equations of the rotor axis and the pads can be written as:

$$
\begin{aligned}
M \ddot{x}= & f_{x}\left(x, y, \dot{x}, \dot{y}, A_{1}, \ldots, A_{5}, \dot{A}_{1}, \ldots, \dot{A}_{5}\right) \\
& +M \rho \cos \tau \\
M \ddot{y}= & f_{y}\left(x, y, \dot{x}, \dot{y}, A_{1}, \ldots, A_{5}, \dot{A}_{1}, \ldots, \dot{A}_{5}\right) \\
& -(1 / \sigma)+M \rho \sin \tau, \\
I \ddot{A}_{j}= & T_{j}\left(x, y, \dot{x}, \dot{y}, A_{j}, \dot{A}_{j}\right) \quad(\text { with } j=1, \ldots, 5) .
\end{aligned}
$$

For the pressure model, the Reynolds equation in laminar and isothermal flow is adopted:

$$
\frac{\partial}{\partial \vartheta}\left(h^{3} \frac{\partial p}{\partial \vartheta}\right)+\left(\frac{R}{L}\right)^{2} \frac{\partial}{\partial z}\left(h^{3} \frac{\partial p}{\partial z}\right)=6 \frac{\partial h}{\partial \vartheta}+12 \frac{\partial h}{\partial \tau}
$$

The dimensionless film thickness between journal and pads under the hypothesis of rigid pads and no misalignment assumes the following approximated expression:

$$
\begin{aligned}
h= & 1-x \cos \vartheta-y \sin \vartheta+A_{j} \sin \left(\vartheta_{p j}-\vartheta\right) \\
& -m \cos \left(\vartheta_{p j}-\vartheta\right) .
\end{aligned}
$$

The components $f_{x}$ and $f_{y}$ of the hydrodynamic force and the moment $T_{j}$ acting on the $j$ th pad with respect to the pivot can be calculated as follows:

$$
\left\{\begin{array}{l}
f_{x} \\
f_{y}
\end{array}\right\}=-\sum_{j=1}^{5} \int_{-0.5}^{0.5} \int_{\vartheta_{j 1}}^{\vartheta_{i 2}} p(\vartheta, z)\left\{\begin{array}{c}
\cos \vartheta \\
\sin \vartheta
\end{array}\right\} \mathrm{d} \vartheta \mathrm{d} z
$$

$$
T_{j}=\int_{-0.5}^{0.5} \int_{\vartheta_{j 1}}^{\vartheta_{j 2}} p(\vartheta, z) \sin \left(\vartheta_{p j}-\vartheta\right) \mathrm{d} \vartheta \mathrm{d} z
$$

Integrating Eq. (2) with finite differences gives the pressure on the pads, and then with Eqs. (4) and (5) gives the hydrodynamic forces and the moments (Pagano et al., 1997).

Finally, numerical integration of the motion equations (1) using a Runge-Kutta method provides the trajectories of the journal and the oscillations of the pads which define the bearing's theoretical behaviour.

In the case of a balanced rotor, the static characteristics are obtained by imposing the equilibrium conditions between the external load and the hydrodynamic forces:

$$
\left\{\begin{array}{l}
f_{x}\left(x, y, 0,0, A_{j}, 0\right)=0 \\
f_{y}\left(x, y, 0,0, A_{j}, 0\right)=1 / \sigma, \\
T_{j}\left(x, y, 0,0, A_{j}, 0\right)=0 \quad(\text { with } j=1, \ldots, 5) .
\end{array}\right.
$$

The theoretical analysis of the system dynamic behaviour is reported in Pagano et al. (1995; 1997), Brancati et al. (1996). Figures 2 and 3 give only an example of the results of the mathematical model: the system's stationary characteristics as the pad offset varies (Fig. 2) and two orbits described by the journal axis with synchronous (Fig. 3(a)) and subsynchronous (Fig. 3(b)) speeds as indicated by

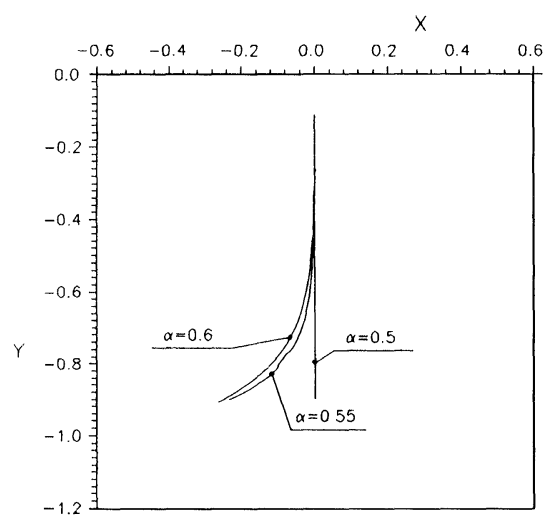

FIGURE 2 Centre loci for different offset values $(\alpha)$. 
(a)

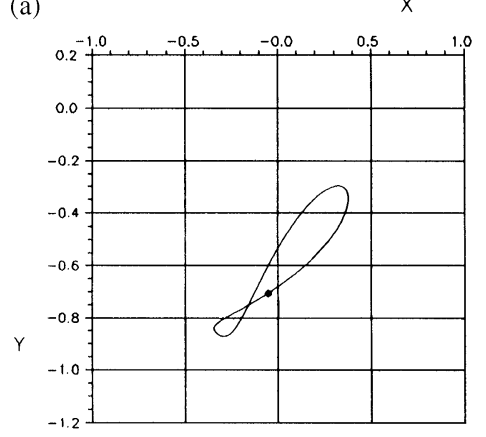

(b)

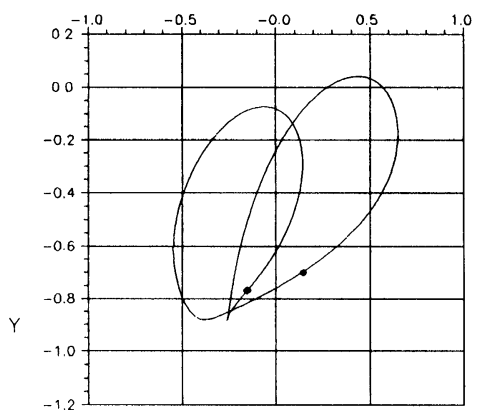

FIGURE 3 (a) Synchronous orbit for $\sigma=2.0, \rho=0.3$ (b) Subsynchronous orbit for $\sigma=2.4, \rho=0.3$.

the presence on the orbits of one or two timemarkers respectively. The ' 8 -shape' orbit in Fig. 3(a) is due to the presence of a second order ultraharmonic component. The orbits are relative to the parameter values reported in Table I.

\section{THE EXPERIMENTAL RIG}

The experimental equipment is made up of a rigid rotor driven by an electric motor supported on two journal bearings with five tilting pads. The bearing supports are fixed to a steel frame fitted to a concrete base (Fig. 4). The rotor is a solid steel cylinder in the centre plane of which two steel rings each with a hole drilled in the axial direction are fitted: modifying the relative angular position between the two rings makes it possible to continuously vary the rotor's unbalance " $e$ ". The static unbalance is thus zero if the two holes are set at a $180^{\circ}$ angle and reaches a maximum if the relative rotation angle between the holes is $0^{\circ}$.

The rotor can be considered to be 'rigid' as the first critical flexural speed is at about 25000 RPM, which is more than twice the maximum rotation speed reached in the tests (10000 RPM). Trough impact hammer tests, with rotor at rest, was ascertained that the system rotor-supports present the first natural frequency around 7600 RPM. This circumstance has an influence on some experimental results in case of high rotor unbalance.

The rotor is driven by an asynchronous electric motor $(3.7 \mathrm{~kW})$ via a toothed belt with a transmission ratio of 0.5 . Rotation speed can be continuously varied by means of a static frequency converter.

The toothed belt transmits the motion to the driven pulley which is fitted onto a shaft whose supports are fixed to the base: in this way the action of the toothed belt is absorbed by the shaft's ball bearing supports and does not affect the dynamics of the rotor. The shaft's rotation motion is transmitted to the rotor via a double universal joint which, as it does not transmit transversal forces, does not affect the rotor's orbital motion. Each pad rolls on its back with an offset of 0.6 ; the geometry of the bearing also gives a geometric preload value of zero.

The oil is fed to the bearings by a lubrication circuit and a gear pump with a by-pass for flow-rate regulation; the supply pressure is indicated on a manometer fitted in the section of circuit upstream of the bearings.

Lubricant temperature can be regulated as desired using a water cooling heat-exchanger or a thermostatic bath.

The system is equipped with a data acquisition unit for measuring the important parameters of the experimental investigation. In particular, the orbits described by the rotor axis are measured with two pairs of eddy current proximity transducers. Each pair of transducers is fixed on the support of a bearing and measures the rotor's radial displacements along two orthogonal directions.

The temperature of the lubricant as it leaves the bearings is measured by copper-constantan 


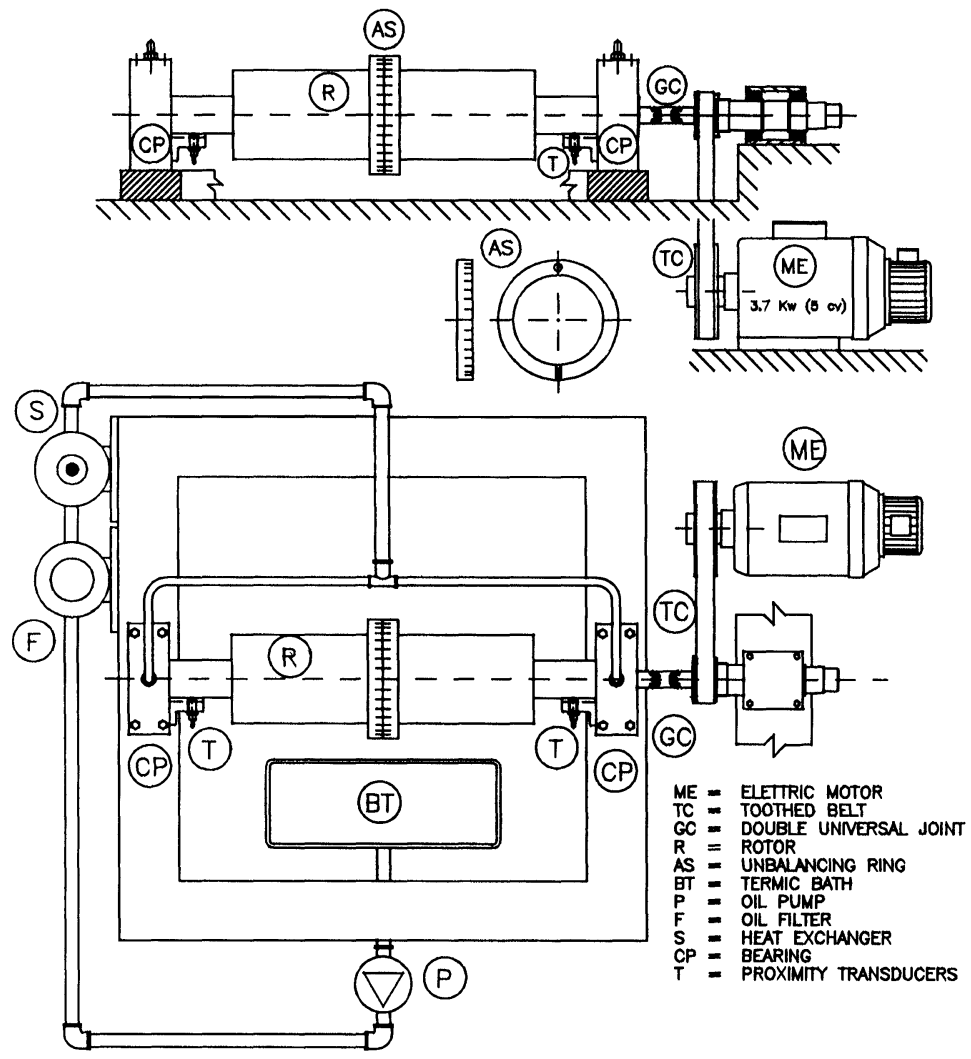

FIGURE 4 Sketch of the test rig.

TABLE I Main characteristics of the test system

Bearing length $L$

Pad radius $R_{\mathrm{p}}$

Bearing radius $R_{\mathrm{b}}$

Journal radius $R$

Pad radial clearance $C_{\mathrm{p}}=R_{\mathrm{p}}-R$

Bearing radial clearance $C_{\mathrm{b}}=R_{\mathrm{b}}-R$

Distance between bearings

Geometrical preload $m$

Offset

Angular pad extension

$L / D$

Rotor mass $M$

Pad mass moment of inertia

Unbalancing mass $m_{\mathrm{f}}$

Dimensionless unbalance $\rho=e / C$

thermocouples. The rotor's rotation speed is measured using an optical tachometer. The lubricant used in the tests is a paraffin-base oil whose viscosity was measured using a "Cannon Fenske" capillary viscosimeter at $40^{\circ} \mathrm{C}$ and $100^{\circ} \mathrm{C}$ and the viscosity at test temperature was calculated using Walther's law. The lubricant has a density $\delta=875 \mathrm{~kg} / \mathrm{m}^{3}$ and the following viscosity values, $\mu_{40^{\circ} \mathrm{C}}=0.027 \mathrm{Pas}$ and $\mu_{100^{\circ} \mathrm{C}}=0.0045 \mathrm{Pas}$. The main characteristics of the test system are reported in Table I.

\section{EXPERIMENTAL RESULTS}

Since it was not possible to reach the high rotation speeds of turbo-machines, in order to simulate true operating conditions in the laboratory and thus reproduce the usual Sommerfeld numbers, the radial clearance of the experimental model was fixed greater than normal and the oil viscosity value was also properly chosen. The tests showed that the rotor dynamics are unaffected by the 
value of the lubricant supply rate which was deliberately high in order to contain the temperature variations inside the bearing as the rotation speed varied. Numerous tests were conducted in different operating conditions and for different unbalance values; each test was carried out several times to ascertain its repeatability.

The results of a series of tests carried out with rotor speed ranging between 2000 and $10000 \mathrm{RPM}$ and with oil temperature regulated at $30^{\circ} \mathrm{C}$ and $60^{\circ} \mathrm{C}$, giving Sommerfeld numbers between 0.2 and 2 are reported below.

The bearing centre was determined pulling, with rotor at rest, the journal in the space between two adjacent pads and detecting its position: repeating this operation for the five spaces, it was possible to determine a circle whose centre is the bearing centre.

\subsection{Balanced Rotor}

Firstly some tests were carried out with no unbalance. In agreement with the predictions of the calculation model, since the offset is 0.6 in the case of 'load on pad', the centre loci is not located on the vertical axis: so, as the rotation speed increases, the subsequent equilibrium positions
(Fig. 5) are located on a curve whose trend is qualitatively similar to that represented in Fig. 2.

In Fig. 5 the equilibrium position points at the smaller speeds are the centre of small orbits. In fact, because of residual unbalance the journal centre describes a small amplitude motion around the stationary equilibrium position.

As the speed, and hence the centrifugal force, increases, the motion amplitude also increases slightly (Fig. 6); at 4000 RPM a $\frac{1}{2}$ subsynchronous component appears, i.e. a frequency one half that

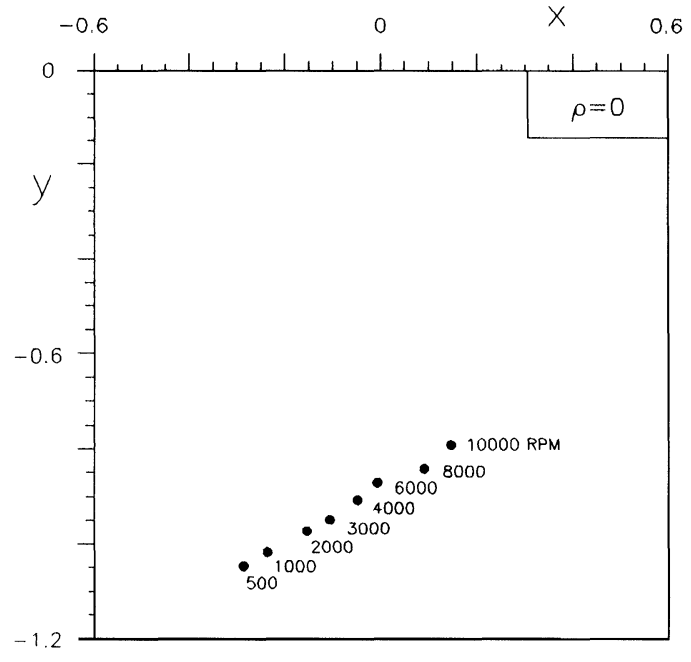

FIGURE 5 Experimental centre loci.
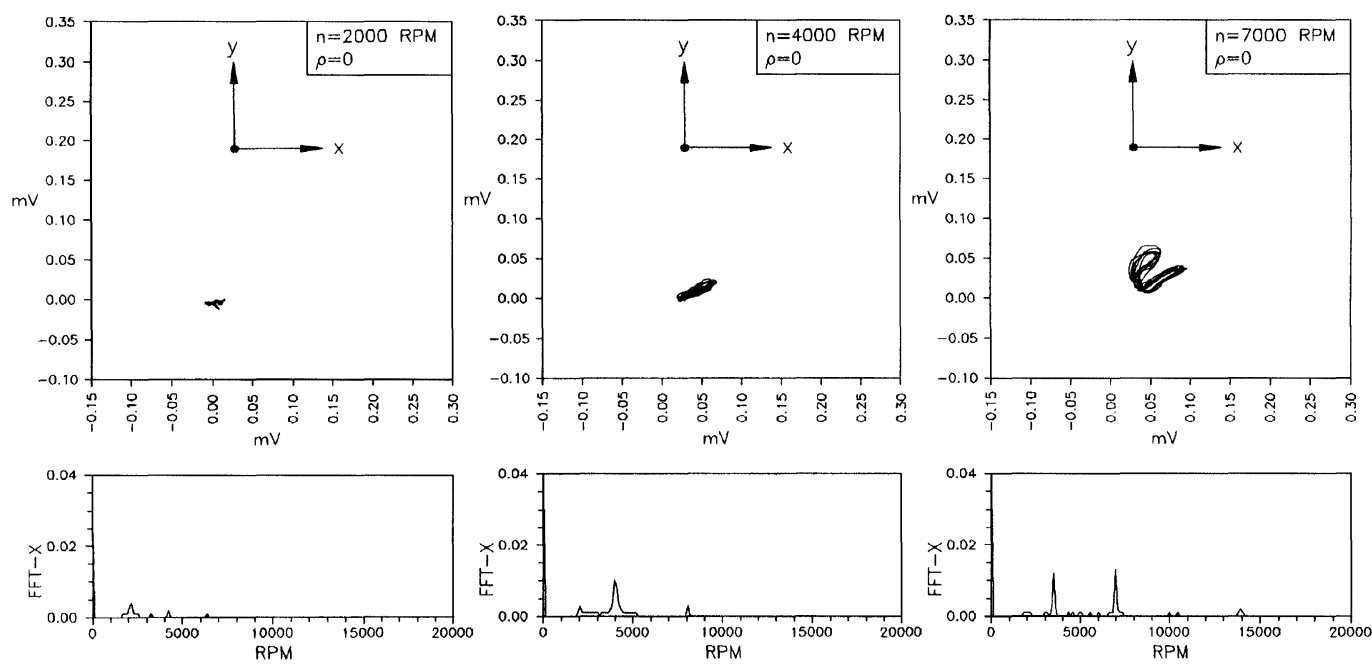

FIGURE 6 Balanced rotor journal orbits $(1 \mathrm{mV}=1 \mathrm{~mm})$. 
one corresponding to the rotation speed, as can be seen from the FFTs performed on a component of the journal motion. This subsynchronous component increases with speed and is more evident at 7000 RPM. For these reasons the determination of the centre loci becomes uncertain at the higher speeds. In the figures $1 \mathrm{mV}$ is equal to $1 \mathrm{~mm}$.

\subsection{Unbalanced Rotor}

This section reports some tests carried out with a dimensionless unbalance value of $\rho=0.15$ and oil temperature of about $30^{\circ} \mathrm{C}$. Analysis of the tests carried out at increasing speeds (Fig. 7) points out that the orbit is initially synchronous with rotation and is horizontally elongated (2000 RPM): in these conditions the journal tilts on the lower pad. After this the orbit's amplitude increases and, above all, is characterised by presence of a $\frac{1}{2}$ subsynchronous component which gives it the typical shapes shown in the figure (4300 RPM).

The appearance of the $\frac{1}{2}$ component at a speed of about 4300 RPM, due to the non-linearity of the hydrodynamic force, was also theoretically
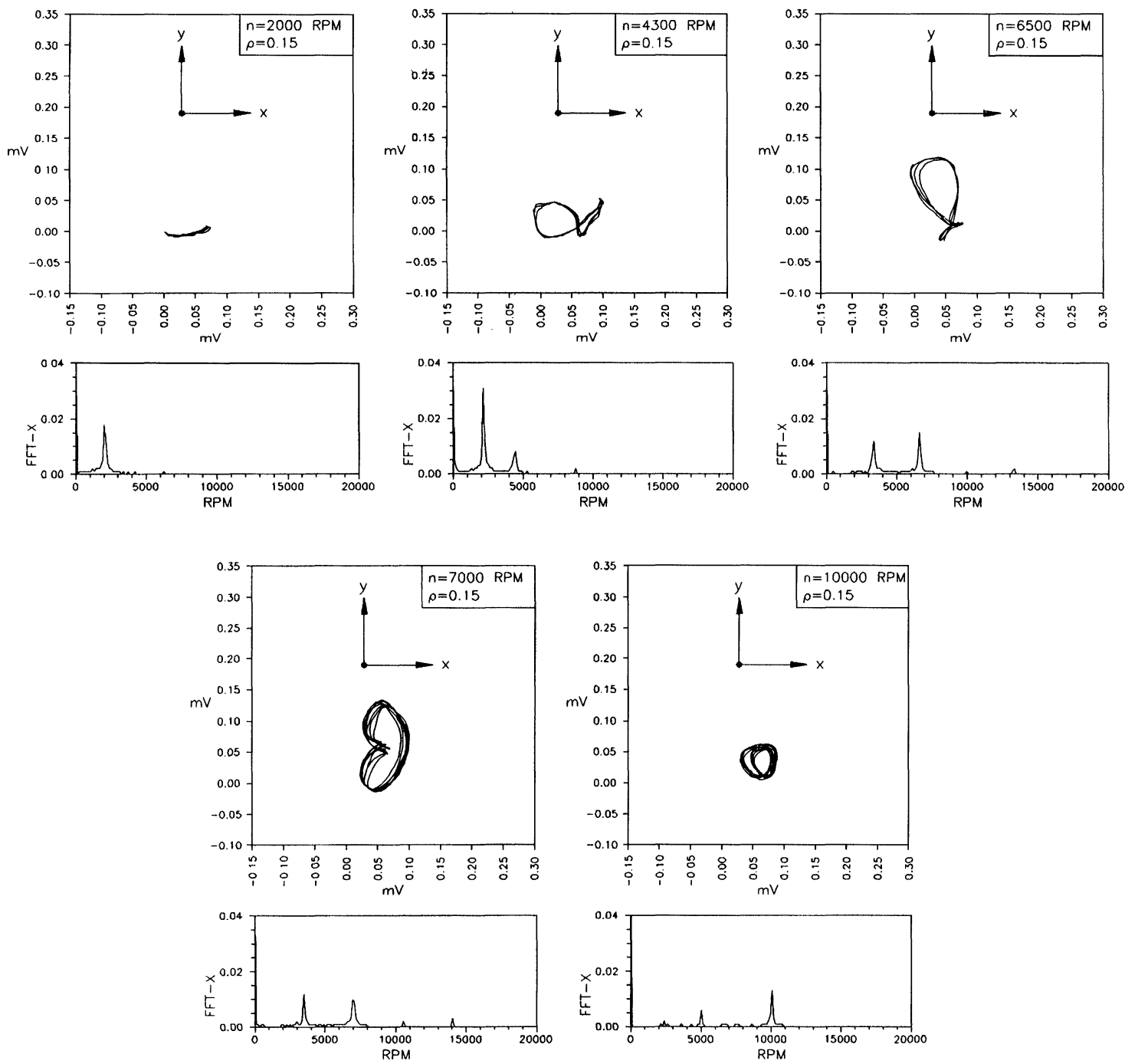

FIGURE 7 Journal orbits for $\rho=0.15$ and $T=30^{\circ} \mathrm{C}(1 \mathrm{mV}=1 \mathrm{~mm})$. 
predicted, although at a higher speed. This component may be dangerous as it can reach amplitudes even greater than the synchronous one and also because it can itself cause vibrations in other parts of the machine. At 10000 RPM the orbit once again becomes small compared to the unbalance.

Again with an unbalance $\rho=0.15$, but with an oil temperature of $60^{\circ} \mathrm{C}$, giving a Sommerfeld number which is about $\frac{1}{3}$ of the previous case, the orbits shown in Fig. 8 were obtained. In addition to the $\frac{1}{2}$ component, these unusual shape orbits also present $\frac{1}{4}$ and even $\frac{1}{8}$ subsynchronous components.

The following figures (Fig. 9) show tests conducted with an unbalance $\rho=0.3$. As speed increases, the orbit assumes a horizontally elongated shape. At low speeds, as in the previous case, the rotating force makes the journal shift alternately between the two lower side pads and the lower pad tracks the journal motion.

As the rotation speed, and hence the centrifugal force, increases, the non-linear effects are accentuated and the journal motion begins to display ultraharmonic components which give the orbit the characteristic ' 8 ' shape (3200 RPM), as was also predicted by the theoretical model: these ultraharmonic components are more noticeable in the vertical motion signal whose FFT in not reported.

In the tests, for speeds over 3200 RPM the orbit suddenly reaches a very large amplitude even though it remains synchronous: this situation persists up to a speed of about 3800 RPM. The described phenomenon could be ascribed to a ultraharmonic resonance: in fact, the second order harmonic of the journal motion is near the natural frequency of the rotor-support system. These orbits are accompanied by a characteristic 'hammering' noise which could be attributed to the pads hitting against the bearing casing and the shaft due to the oil film rupture.

At higher speeds the $\frac{1}{2}$ sub-synchronous component appears and the orbit amplitude decreases. For further increases in speed the frequency component corresponding to $\frac{1}{2}$ the rotation speed assumes an ever greater importance and reaches a maximum
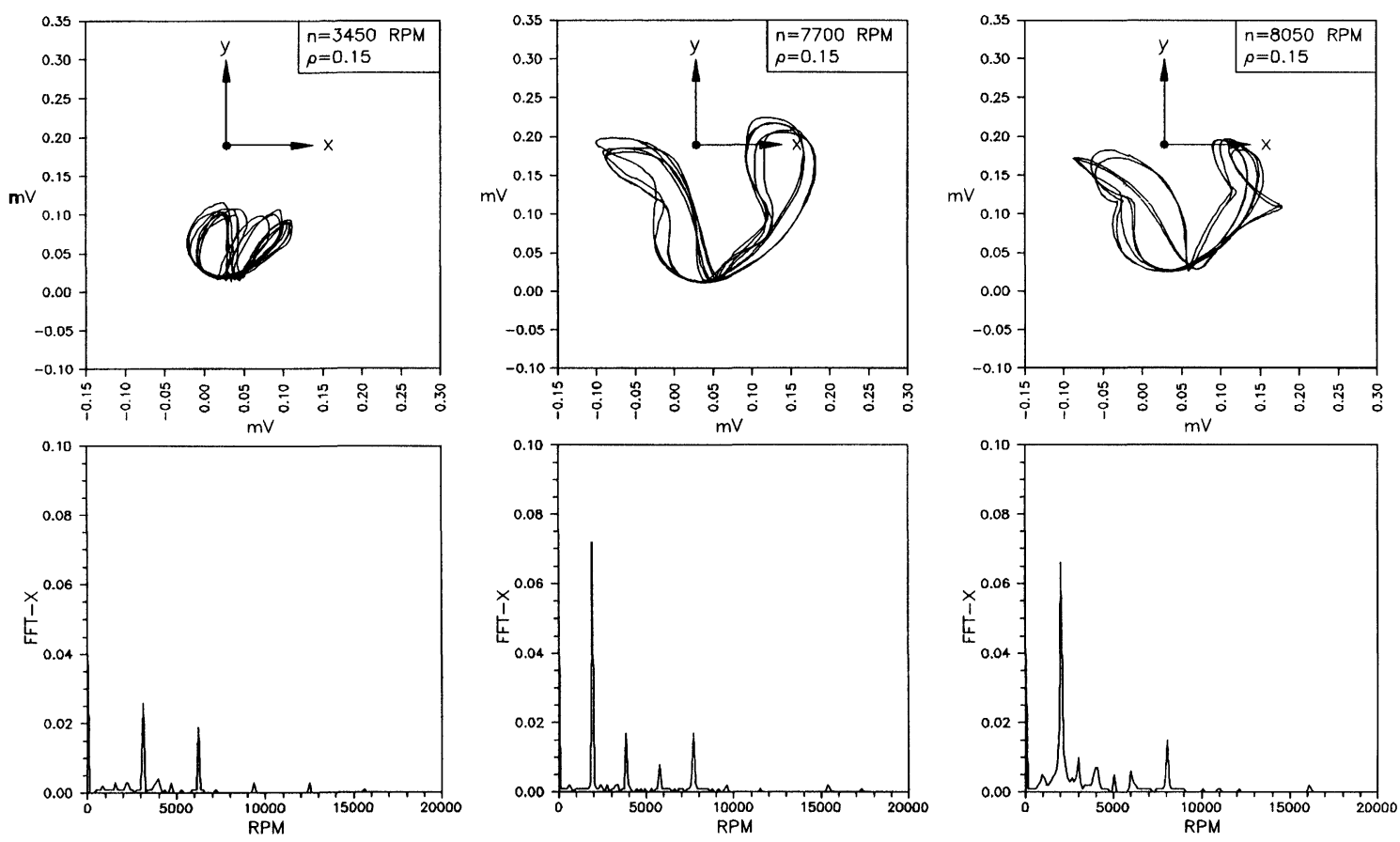

FIGURE 8 Journal orbits for $\rho=0.15$ and $T=60^{\circ} \mathrm{C}(1 \mathrm{mV}=1 \mathrm{~mm})$. 

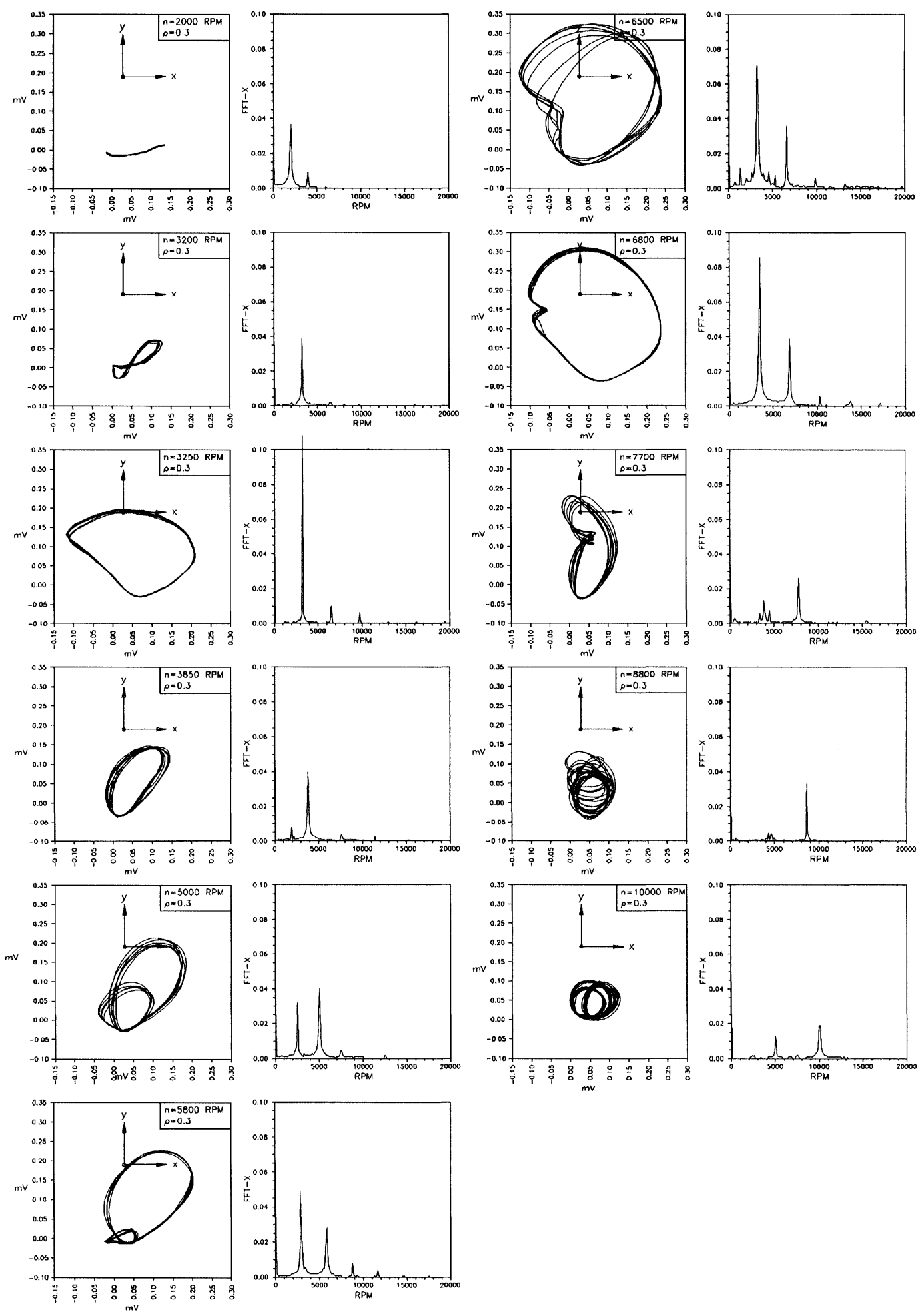

FIGURE 9 Journal orbits for $\rho=0.30$ and $T=30^{\circ} \mathrm{C}(1 \mathrm{mV}=1 \mathrm{~mm})$. 
for speeds double those for which the synchronous component is at a maximum.

After a speed interval during which beat phenomena can be observed (8300 RPM) on the orbit components due to the presence of two components very close to $\frac{1}{2}$, the orbit displays a small amplitude up to the maximum test speed (10000 RPM).

It can therefore be noted that as the amplitude of the forcing action increases, the system displays a different qualitative behaviour. For $\rho=0.30$ the system presents a rotation speed for which the journal motion instantaneously becomes much larger although it remains synchronous; the '8-shape' orbit instantaneously assumes a round shape. Motion amplitude is much larger when the speed is double the previous value and the motion is characterised by a $\frac{1}{2}$ subsynchronous component. At the same speed but with a smaller unbalance ( $\rho=0.15)$ this does not occur and as speed increases the orbit gradually changes shape until the subsynchronous component appears.

In some cases $\frac{1}{3}$ subsynchronous and nonperiodic motions were observed but it is uncertain whether steady-state operating conditions were reached, especially as far as the temperature inside the bearing is concerned.

\section{CONCLUSIONS}

The experimental investigation carried out on a model of a rigid rotor supported on journal bearings with five tilting pads points out some irregular and even dangerous dynamic behaviour of the rotor-bearings system for a given operating range. This behaviour, which is caused by unbalance and is characterised by large amplitudes in the journal motion and the presence of subsynchronous and ultrasynchronous motion components, cannot be entirely predicted by theoretical models because of the high number of factors affecting it. Since the design phase should now envisage a preliminary dynamic analysis of the rotor-bearings system so as to avoid the occurrence of dangerous operating conditions and in order to ensure that this analysis is as complete and true-to-life as possible, it would be worthwhile targeting research on obtaining a more reliable theoretical modelling of the bearings.

In order to understand deeply the described phenomena at the laboratory of the Dipartimento di Ingegneria Meccanica per l'Energetica, a new series of tests have been planned with a further instrumentation of test rig that allows even to detect the motions of the pads.

\section{NOMENCLATURE}

\begin{tabular}{|c|c|}
\hline$A_{j}$ & $\delta R / C_{\mathrm{p}}$ \\
\hline$C_{\mathrm{b}}$ & bearing radial clearance \\
\hline$C_{\mathrm{p}}$ & pad radial clearance \\
\hline$D=2 R$ & bearing diameter \\
\hline $\bar{I}$ & $\begin{array}{l}\text { mass moment of inertia } \\
\text { of pads }\end{array}$ \\
\hline$I$ & $\begin{array}{l}\bar{I} \omega^{2} / R W \sigma=\text { dimension- } \\
\text { less mass moment of } \\
\text { inertia of pads }\end{array}$ \\
\hline$L$ & bearing length \\
\hline $\bar{M}$ & half rotor mass \\
\hline$M$ & $\begin{array}{c}\bar{M} \omega^{2} C_{\mathrm{p}} / \mathrm{W}=\text { dimension- } \\
\text { less half rotor mass }\end{array}$ \\
\hline$m$ & geometrical preload \\
\hline$R$ & bearing radius \\
\hline$W$ & externally applied load \\
\hline $\bar{x}, \bar{y}, \bar{z}$ & coordinates \\
\hline$x, y, z=\bar{x} / C, \bar{y} / C, \bar{z} / L$ & $\begin{array}{l}\text { dimensionless } \\
\text { coordinates }\end{array}$ \\
\hline$\alpha$ & pad offset \\
\hline$e$ & rotor unbalance \\
\hline$\delta$ & pad deflection angle \\
\hline$\vartheta$ & $\begin{array}{l}\text { circumferential } \\
\text { coordinate }\end{array}$ \\
\hline$\mu$ & dynamic oil viscosity \\
\hline$\rho=e / C$ & $\begin{array}{l}\text { dimensionless rotor } \\
\text { unbalance }\end{array}$ \\
\hline$\sigma=(\mu \omega R L / W)\left(R / C_{\mathrm{p}}\right)^{2}$ & Sommerfeld number \\
\hline$\tau=\omega t$ & dimensionless time \\
\hline$\omega$ & rotor angular speed \\
\hline
\end{tabular}




\section{References}

Adams, M.L. (1980). Non-linear dynamics of flexible multi-bearing rotors, Journal of Sound and Vibration, 71, $129-144$.

Adams, M.L. and Payandeh, S. (1983). Self-excited vibration of statically unloaded pads in tilting-pad journal bearings, ASME Journal of Lubrication Technology, 105 $377-385$.

Adams, M.L. and McCloskey, T.H. (1984). Large unbalance vibration in steam turbine-generator sets, IMechE, C306/84.
Brancati, R., Rocca, E. and Russo, R. (1996). Non linear analysis of a rigid rotor on tilting pad journal bearings, Tribology International, 29(7), 571-578.

Jones, G.J. and Martin, F.A. (1978). Geometry effects in tiltingpad journal bearings, ASLE Transactions, 22, 227-244.

Pagano, S., Rocca, E., Russo, M. and Russo, R. (1995). Dynamic behaviour of tilting-pad journal bearings, Proc. Instn. of Mechanical Engineering, Part J, 209(J4), 275-285.

Pagano, S., Rocca, E., Russo, M. and Russo, R. (1997) Instability threshold of a rigid rotor-tilting pad journal bearings system, International Journal of Rotating Machinery, 3(3), 199-213 


\section{ait \\ ENERGY MATERIALS}

M A N E Y publishing

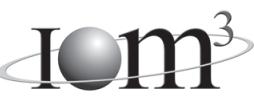

\section{Materials Science \& Engineering for Energy Systems}

Maney Publishing on behalf of the Institute of Materials, Minerals and Mining

The Institute of Materials, Minerals \& Mining

Economic and environmental factors are creating ever greater pressures for the efficient generation, transmission and use of energy. Materials developments are crucial to progress in all these areas: to innovation in design; to extending lifetime and maintenance intervals; and to successful operation in more demanding environments. Drawing together the broad community with interests in these areas, Energy Materials addresses materials needs in future energy generation, transmission, utilisation, conservation and storage. The journal covers thermal generation and gas turbines; renewable power (wind, wave, tidal, hydro, solar and geothermal); fuel cells (low and high temperature); materials issues relevant to biomass and biotechnology; nuclear power generation (fission and fusion); hydrogen generation and storage in the context of the 'hydrogen economy'; and the transmission and storage of the energy produced.

As well as publishing high-quality peer-reviewed research, Energy Materials promotes discussion of issues common to all sectors, through commissioned reviews and commentaries. The journal includes coverage of energy economics and policy, and broader social issues, since the political and legislative context influence research and investment decisions.

\section{CALL FOR PAPERS}

Contributions to the journal should be submitted online at http://ema.edmgr.com

To view the Notes for Contributors please visit: www.maney.co.uk/journals/notes/ema

Upon publication in 2006, this journal will be available via the Ingenta Connect journals service. To view free sample content online visit: www.ingentaconnect.com/content/maney

For further information please contact:

Maney Publishing UK

Tel: +44 (0)113 2497481 Fax: +44 (0)1132486983 Email: subscriptions@maney.co.uk

or

Maney Publishing North America

Tel (toll free): 8662975154 Fax: 6173546875 Email: maney@maneyusa.com

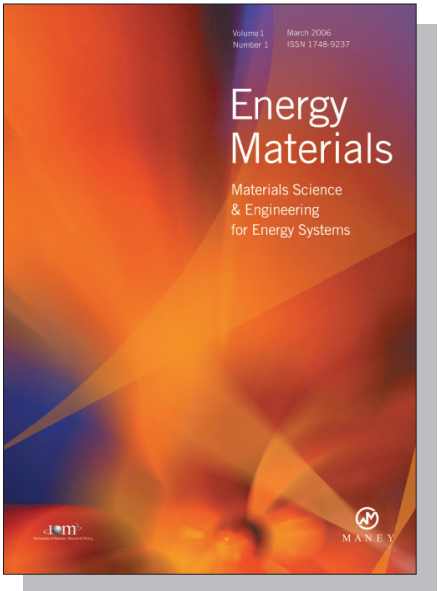

EDITORS

Dr Fujio Abe

NIMS, Japan

Dr John Hald, IPL-MPT, Technical University of Denmark, Denmark

Dr R Viswanathan, EPRI, USA

\section{SUBSCRIPTION INFORMATION}

Volume 1 (2006), 4 issues per year

Print ISSN: 1748-9237 Online ISSN: 1748-9245

Individual rate: $£ 76.00 / U S \$ 141.00$

Institutional rate: $£ 235.00 /$ US $\$ 435.00$

Online-only institutional rate: $£ 199.00 / U S \$ 367.00$

For special $\mathrm{IOM}^{3}$ member rates please email

subscriptions@maney.co.uk

\section{For further information or to subscribe online please visit www.maney.co.uk}



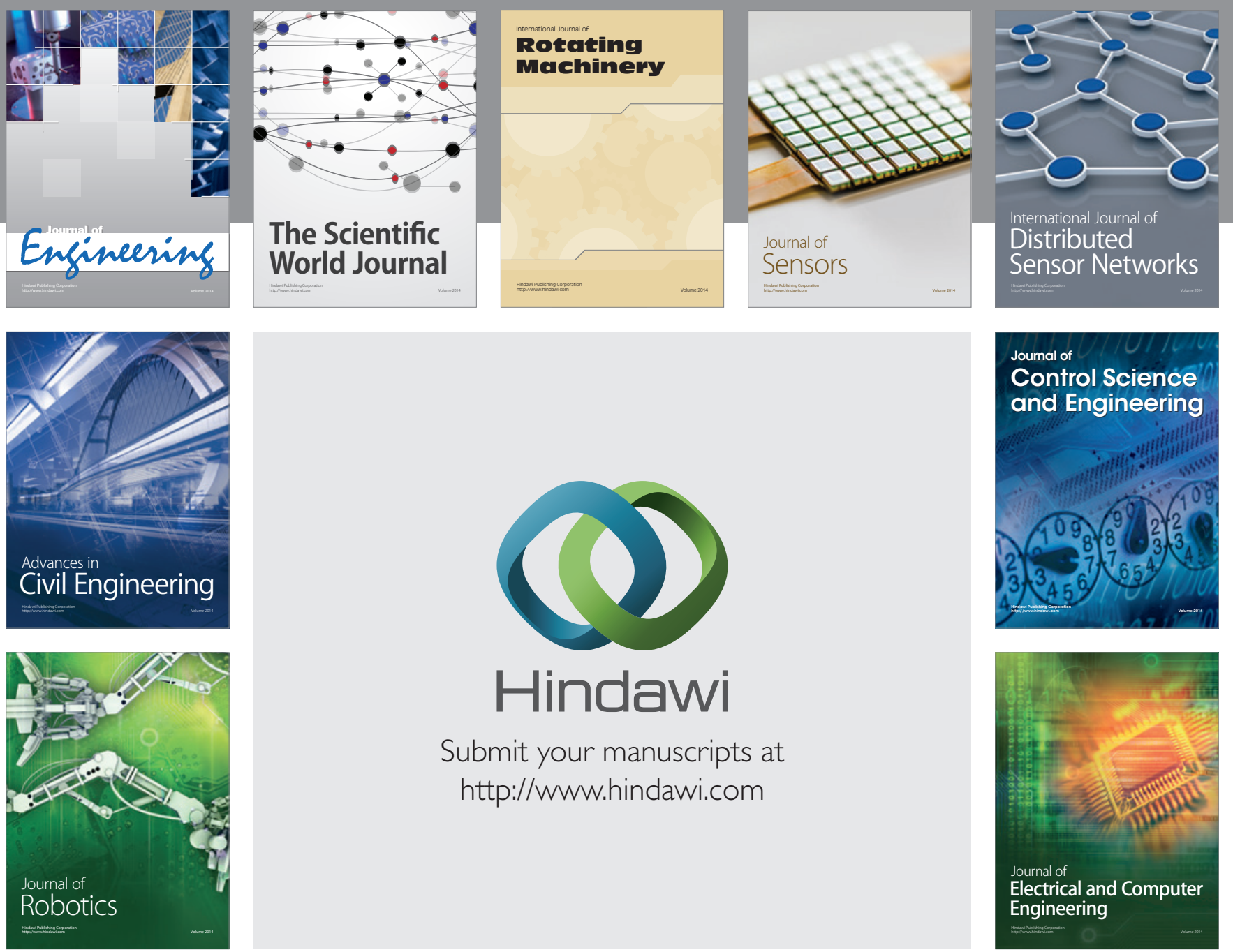

Submit your manuscripts at

http://www.hindawi.com
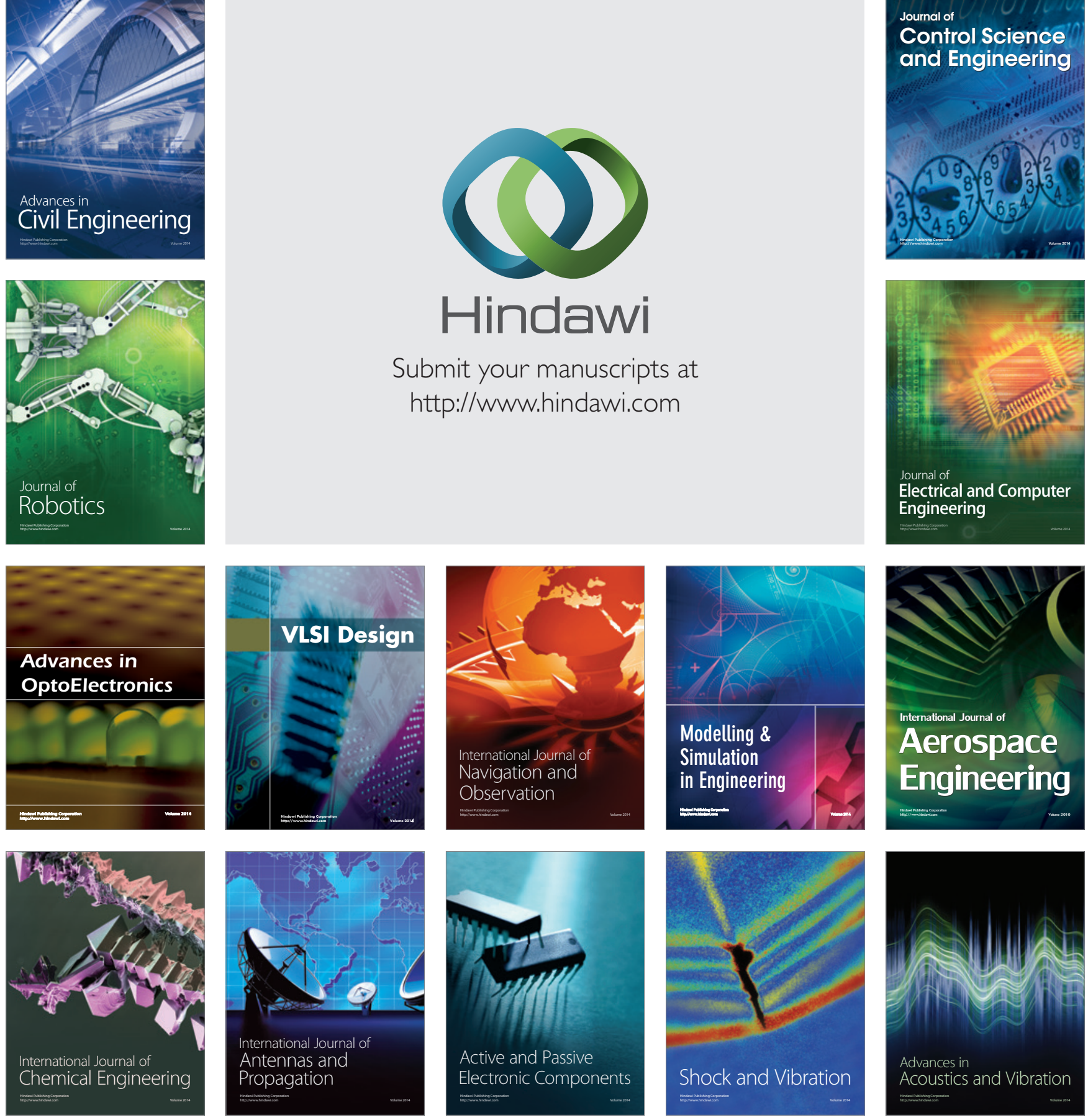